\title{
Recollection of children following intensive care
}

\author{
S Playfor, D Thomas, I Choonara
}

\begin{abstract}
Background and aims-The recollections of critically ill children following discharge from the paediatric intensive care unit (PICU) have not previously been described. We have interviewed such children to establish the nature of their recollections.

Methods-Children aged 4 years and above were interviewed following discharge from the PICU at the Queens Medical Centre, Nottingham, either in hospital or at home, using a semistructured interview. Their recollections were recorded and interpreted by content analysis.

Results-A total of 38 interviews were carried out; 44 specific recollections were reported, the majority being neutral $(60 \%)$ or positive $(25 \%)$. Only $15 \%$ of recollections were negative. Negative recollections related to aspects of medical care and environmental factors. No child treated with neuromuscular blocking agents remembered any period of therapeutic paralysis.

Conclusions-Children's recollections of PICU are mainly neutral or positive. Mechanically ventilated children sedated with midazolam and morphine remember little of endotracheal intubation. (Arch Dis Child 2000;83:445-448)
\end{abstract}

Keywords: recall; paediatric intensive care; midazolam

There have been no studies describing the recollections of critically ill children following intensive care admission. Studies have shown that adult patients frequently have unpleasant recollections of the intensive care unit, and often remember periods of mechanical ventilation and therapeutic paralysis. ${ }^{1}$

We have assessed the recall of children aged 4 years and above following discharge from a paediatric intensive care unit (PICU) by means of a single semistructured interview.

Paediatric Intensive Care Unit, Queens Medical Centre, Nottingham, UK D Thomas

Academic Division of Child Health

(University of Nottingham), Derbyshire Children's

Hospital, Uttoxeter

Road, Derby, UK

I Choonara

Correspondence to:

Dr Playfor

playfor@sickkids.on.ca

Accepted 3 April 2000 was approved by the local ethics committe Two groups of children were studied. Group A included children aged 4 years and above admitted to the PICU over a period of 12 consecutive weeks from the onset of the study. Group B included similar children who had been mechanically ventilated in the seven months prior to the onset of the study.

GROUP A

Once it was apparent that their child was likely to survive PICU admission, parents were asked for their written informed consent. Children with learning difficulties severe enough to preclude interview were noted and excluded. Following their discharge children were seen in general ward areas and a semistructured interview with a maximum of 16 questions was applied (Appendix 1). Standard prompts were used with question 1 , "Do you remember being on the intensive care unit?" to assist children in identifying which part of the hospital was the PICU. A single investigator (SP) carried out all interviews and parents of all younger children were present. Older children were given the option of having parents present. Interviews were tape recorded and lasted for a maximum of 15 minutes. Children were then asked to "draw a picture of what it was like to be on the intensive care unit."

\section{GROUP B}

All similar children who had been mechanically ventilated in the preceding seven months and who we were able to contact by telephone were identified. The parents of these children were contacted by telephone and informed verbal consent was obtained. At a mutually convenient time a single investigator (SP) telephoned the child and interviews were carried out as above. Question number 15, "How do you feel about being back on the ward?" was omitted.

Children's responses were transcribed verbatim from the tape recordings and analysed independently by two investigators (SP and NC). Differences in interpretation between the two investigators were identified and an agreed interpretation arrived at. Responses to question 3, "What do you remember about the intensive care unit?" were assessed by a process of content analysis, grouped into themes, and graded as negative, neutral, or positive. Responses to questions $5,6,13$, and 14 were also grouped into themes. Responses to questions 15 and 16 were independently assessed as being positive, neutral, or negative.

Mechanically ventilated children on our unit receive a standard sedation regime of continuous intravenous infusions of midazolam and morphine with additional oral sedation using chloral hydrate and antihistamines as required. Once adequate sedation is achieved, children requiring neuromuscular blockade receive a continuous infusion of atracurium besylate.

\section{Results}

A total of 38 interviews were carried out: 24 from group A and 14 from group B. There were 45 admissions of children aged 4 years and above to the PICU during the study period. Of those children not interviewed: 11 had pre-existing severe learning difficulties, four suffered ongoing neurological deficits as a result of their illness which precluded 
Table 1 Clinical diagnoses of patients

\begin{tabular}{ll}
\hline Diagnosis & Number \\
\hline Scoliosis repair & 9 \\
General medical & 8 \\
Sepsis & 6 \\
Head injury & 6 \\
Other craniotomy & 5 \\
ENT bleed & 2 \\
General surgery & 1 \\
Burns & 1 \\
\hline
\end{tabular}

interview, three children refused to be interviewed, two were lost to follow up, and one child died. There were no statistically or clinically significant differences between the responses of group A and group B.

The median age of all interviewed patients was 12 years (range $4-16$ years); $47 \%$ were male. Table 1 shows their clinical diagnoses. The median duration of PICU admission was three days (range 1-11 days). Twenty five children $(66 \%)$ were mechanically ventilated and seven $(18 \%)$ were treated with neuromuscular blocking agents. Interviews for group A took place after a median interval of two days following discharge from PICU (range 1-12 days). Interviews from group B took place after a median interval of 16 weeks following discharge from PICU (range 4-28 weeks).

Twenty five children (66\%) were able to remember the PICU and 17 (45\%) knew why they had been there. All those who were not mechanically ventilated could remember the unit although notably only one of the six children $(17 \%)$ admitted with a head injury remembered the PICU.

In response to question 3, "What do you remember about the intensive care unit?" children expressed 44 specific recollections (fig 1); 26 of these were classified as neutral and related mainly to observations of the medical equipment surrounding them, the environment, and how they were feeling. Eleven positive recollections were expressed, the most common of which related to the nursing staff,

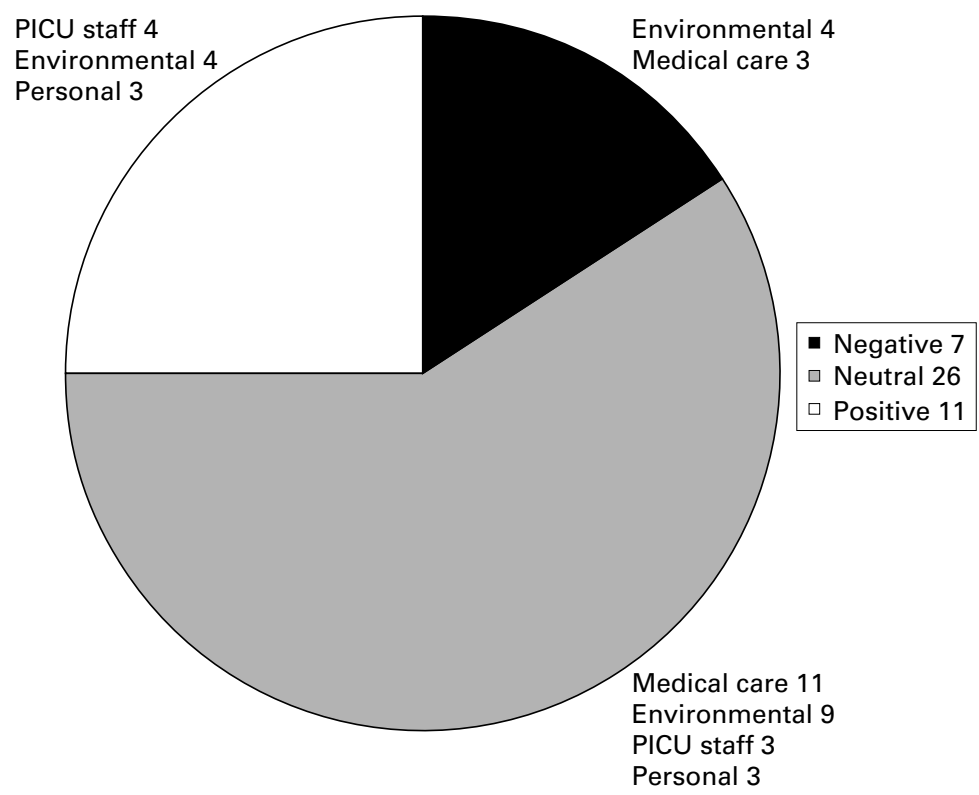

Figure 1 Recollections of PICU. followed by environmental factors such as the television. Seven negative recollections were expressed. Four related to the environment: three complained about noise levels, and one complained about never knowing what time of day it was. The other three negative recollections related to medical care: two regarding nasogastric tubes, and one regarding an endotracheal tube. Only one child said that the PICU was overall a bad place. She could recall no specific bad things and could only add, "I don't like it. I don't like having to go there."

Twenty one children $(55 \%)$ could remember the PICU nursing staff, regarding whom there were 32 specific recollections; 16 related to the provision of nursing care and 13 related to personal interaction such as "being kind" and "talking to me". Only one child could remember the medical staff; "The doctor said 'you look glum, give us a smile"”.

When asked to highlight good things, 26 factors were identified; the most common of these related to the care received by the child: being made better (six statements) and being looked after (four statements). The next most common statements related to the nursing staff and environmental themes; particularly the comfortable, relaxed, or friendly atmosphere on PICU and especially the television and videos. When asked to highlight bad things, 14 factors were identified. The most common of these related to aspects of medical care: nasogastric tubes, needles, and bad tasting medicine. The next most common group was environmental factors such as noise or an uncomfortable bed. Four personal factors were identified: being unable to speak because of the endotracheal tube, lack of sleep, not knowing the time of day, and being hungry. One 7 year old boy was concerned that the PICU "could be quite dangerous with all those sharp things around".

On direct questioning 11 children (29\%) remembered being in pain. Eight children $(21 \%)$ said that they had been scared and six (16\%) complained of being unable to sleep because of noise or discomfort: "I couldn't sleep because I had to stay on my back. I'd be awake from about one o'clock in the morning." Eight children (21\%) complained of being thirsty. Two children experienced unusual dreams following PICU discharge: one dreamt about "doctors putting lines into me" but said that they were not upsetting, and the other reported "some really weird dreams that I can't explain. They were a bit frightening".

Of the 25 children who had been mechanically ventilated, 12 (48\%) were able to remember PICU. Four children (16\%) had some recollection of mechanical ventilation: one child reported, "it felt like normal breathing", one child remembered the tube being down her throat and being unable to speak because of it, and two children remembered coughing as the endotracheal tube was removed. Seven children had been treated with continuous infusions of neuromuscular blocking agents and none had any recollection of therapeutic paralysis. Because of the low levels of recall in children treated with infusions of midazolam 


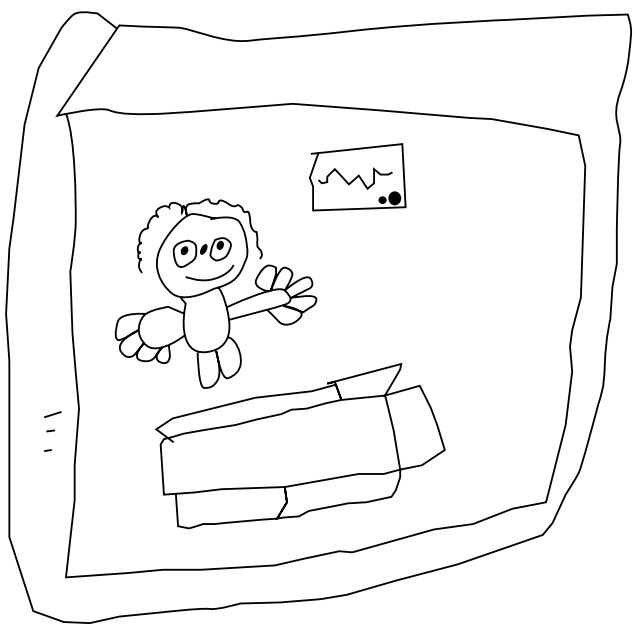

Figure 2 Child's drawing of "what it was like to be on the intensive care unit”.

there was no correlation between severity of illness, or depth of sedation, and subsequent recall.

Of those children interviewed in hospital $88 \%$ were positive about their move to a general ward area. Overall, $79 \%$ of children felt neutral regarding any future readmission to PICU and $13 \%$ felt negative.

Only nine children were willing to draw pictures; the majority were either feeling too unwell or were too embarrassed. The majority drew themselves lying in bed or standing in the hospital such as in fig 2 .

\section{Discussion}

Initial reports of recollection following intensive care were based on the frequently disturbing personal accounts of adults highlighting the inability to communicate, pain, fear, and hallucinations. $^{2-4}$ Subsequent studies have shown that up to $50 \%$ of adult patients may remember extensive details of treatment received, including mechanical ventilation and therapeutic paralysis. ${ }^{5-10}$ In a more recent study, $36 \%$ of adult patients recalled therapeutic paralysis and highlighted temporal disorientation, sleep disturbance, and difficulty in breathing as major negative experiences. ${ }^{11}$ It has been shown that the degree of recall in adult patients is correlated with the severity of their illness, ${ }^{12}$ and other authors have commented on the potential link between sedation and subsequent recall. ${ }^{13}$

We have interviewed children over a broad age range, following the advice of a child psychologist, and do not feel that the age of the children influenced their responses. Similarly we interviewed children in group B after a variable interval following discharge which may have influenced their recall, although we were reassured by the lack of difference in the nature of responses between groups $\mathrm{A}$ and $\mathrm{B}$, and by the findings of adult investigators who found recall of critical care experience is not significantly affected by the time elapsed since admission. ${ }^{10}$

We have shown that children interviewed following discharge from PICU have essentially neutral recollections, with any negative recol- lections focusing on uncomfortable aspects of medical care or environmental factors. Almost one third of the children in this study remembered being in pain, a similar result to that found in a recent adult study. ${ }^{14}$ Effective management of pain is increasingly recognised as an important element of critical care; with modern anaesthetic and analgesic techniques the quality of this aspect of care should be improved.

The children in this study remembered little of mechanical ventilation and nothing of therapeutic paralysis. Only one ventilated child could clearly remember the presence of the endotracheal tube, and she highlighted the anxiety that resulted from inability to communicate. The traditional goals of sedation have been to facilitate mechanical ventilation, reduce anxiety and distress in the child, and allow for tolerance of diagnostic and therapeutic procedures..$^{15}$ Additional benefits may include reduced patient recall, which may be an important factor in reducing subsequent psychological morbidity, ${ }^{16}$ and may reduce the incidence of post-traumatic stress disorder following critical illness. ${ }^{17}$

Midazolam is recognised as an effective sedative agen $\mathrm{t}^{18}$ and is widely used in critically ill children worldwide. ${ }^{19} 20$ The benzodiazepines are excellent agents for inducing antegrade amnesia without impairing the ability to retrieve previously learned information. ${ }^{21}$ Midazolam has been shown to reduce the recollection of critically ill adult patients, ${ }^{12}$ although this may not be true at low doses. ${ }^{22}$ It is well known that the handling of midazolam varies between age groups, ${ }^{23}$ and that wide interindividual variations occur in the pharmacokinetics of midazolam in critically ill children..$^{24}$ Our study suggests that midazolam has a significant amnesic effect when administered by continuous infusion to critically ill children, which adds to its profile as a useful sedative agent in this group. Further studies involving larger numbers of children would be required to determine if the depth or quality of sedation obtained with midazolam was correlated with recall. The effects on subsequent patient recall should be considered when assessing the efficacy of sedation regimes in intensive care.

We are grateful for the assistance of Dr Neal Chilvers in the data analysis of this paper.

\section{Appendix 1: Recall questions}

1 Do you remember being on the intensive care unit? (If "No"; The place where you were before you were brought here. The place where you were very poorly. If still "No" ask Questions 2, 11, 15, 16).

2 Do you know why you were admitted to the unit?

3 What do you remember about the intensive care unit?

4 Overall was it good or bad?

5 What were the good things?

6 What were the bad things?

7 Were you ever in pain?

8 Were you ever scared? 
9 Could you sleep when you were tired?

10 Could you get a drink when you were thirsty?

11 Have you had any bad dreams? (If "Yes"; What were they about?)

[12] Do you remember being on the breathing machine? (If "Yes"; What was it like?)

13 What were the noises you could hear?

14 Do you remember the nurses? (If "Yes"; What were they doing?)

[15] How do you feel about being back on the ward?

16 If you got poorly again and had to go back to the intensive care unit how would you feel about it?

Key: [ ] indicates optional questions.

1 Cheng EY. Recall in the sedated ICU patient. 7 Clin Anesth 1996;8:675-8.

2 Parker MM, Schubert W, Shelhamer JH, et al. Perceptions of a critically ill patient experiencing therapeutic paralysis in an ICU. Crit Care Med 1984;12:69-71.

Anonymous. Both ends of the stethoscope. Cardiac arrest. Lancet 1969;2:262-4.

4 Bevan JR. Polyneuropathy. Lancet 1969;1:1310.

5 Hewitt PB. Subjective follow-up of patients from a surgical intensive therapy ward. BMF 1970;4:669-73.

6 Green A. An exploratory study of patients' memory recall of their stay in an adult intensive therapy unit. Intensive Crit Care Nurs 1996;12:131-7.

7 Simpson TF, Armstrong S, Mitchell P. American Association of Critical-Care Nurses demonstration project: patients' recollections of critical care. Heart Lung 1989;18: 325-32.

8 Holland C, Cason CL, Prater LR. Patients' recollections of critical care. Dimens Crit Care Nurs 1997;16:132-41.
9 Turner JS, Briggs SJ, Springhorn HE, et al. Patients' recollection of intensive care unit experience. Crit Care Med recollection of inter

10 Bergbom-Engberg I, Haljamae H. Patient experiences during respirator treatment-reason for intermittent positivepressure ventilation treatment and patient awareness in the intensive care unit. Crit Care Med 1989;17:22-5.

11 Wagner BK, Zavotsky KE, Sweeney JB, et al. Patient recall of therapeutic paralysis in a surgical critical care unit. Pharmacotherapy 1998;18:358-63.

12 Bion JF. Sedation and analgesia in the intensive care unit. Hospital Update 1988;14:1272-86.

13 Gow GL. Influence of sedation regimens. British fournal of Intensive Care 1995;5:112-16.

14 Simini B. Patients' perceptions of intensive care, Lancet 1999;354:571-2.

15 Shelley MP. Sedation in the ITU. Care of the Critically Ill 1998;14:85-8

16 Fricchione G, Kohane DS, Daly R, et al. Psychopharmacology in the intensive care unit. New Horiz 1998;6:353-62.

17 Landolt MA, Boehler U, Schwager C, et al. Post-traumatic stress disorder in paediatric patients and their parents: an exploratory study. F Paediatr Child Health 1998;34:539-43.

18 Notterman DA. Sedation with intravenous midazolam in the pediatric intensive care unit. Clin Pediatr 1997;36:44954.

19 Matthews AJ. An audit of sedation, analgesia and muscle relaxation in paediatric intensive care in the United relaxation in paediatric intensive care in
Kingdom. Paediatr Anaesth 1993;3:107-15.

20 Marx CM, Rosenberg DI, Ambuel B, et al. Pediatric intensive care sedation: survey of fellowship training programs. Pediatrics 1993,91:369-78.

21 Ghoneim MM, Mewaldt SP. Benzodiazepines and human memory: a review. Anesthesiology 1990;72:926-38.

22 Henderson A, Dipplesman J, Miller J. Failure of intravenous low dose midazolam to influence memory recall in drug paralysed post-operative patients sedated with papaveretum. Aust Crit Care 1994;7:22-4.

23 Park GR, Navapurkar V. Sedation in the critically ill patient - the place of midazolam. Care of the Critically 1994;10:5-9.

24 Hughes J, Gill AM, Mulhearn H, et al. Steady-state plasma concentrations of midazolam in critically ill infants and children. Ann Pharmacother 1996;30:27-30. 